\title{
Beyond the game: the legacy of Bill Masterton
}

\author{
Christopher M. Bonfield, MD, ${ }^{1}$ and Douglas Kondziolka, MD² \\ 1Division of Neurosurgery, Department of Surgery, BC Children's Hospital and University of British Columbia, Vancouver, British \\ Columbia, Canada; and 'Departments of Neurosurgery and Radiation Oncology, NYU Langone Medical Center, New York, \\ New York
}

\begin{abstract}
Bill Masterton is the only man to die of injuries sustained in a National Hockey League (NHL) game. He remains the last fatality in any professional team sport involving a direct in-game injury in North America. While Masterton was originally thought to have suffered a fatal brain injury while being checked on the ice, later analysis of the case revealed evidence of second-impact syndrome and the effects of prior concussions. Masterton's death sparked both an immediate debate in the NHL on whether helmets should be compulsory and the NHL's first vote on mandatory helmet use. Although the subject of mandated helmet use met with resistance in the 10 years after Masterton's death, especially from hockey owners and coaches, the NHL finally legislated helmet use by all players entering the league beginning in the 1979-1980 season.

Several awards, including one recognizing the NHL player who best exemplifies the qualities of perseverance, sportsmanship, and dedication to hockey, have been created in memory of Masterton. However, his legacy extends far beyond the awards that bear his name. His death was the seminal event bringing head safety to the forefront of a game that was both unready and unwilling to accept change. An increase in mainstream media attention in recent years has led to unprecedented public awareness of brain injury and concussion in hockey and other sports. Advances in the diagnosis and treatment of head injury in sports have occurred recently, the impetus for which started over 45 years ago, when Bill Masterton died.
\end{abstract}

http://thejns.org/doi/abs/10.3171/2016.2.FOCUS1558

KEY WORDS traumatic brain injury; neurosurgery; hockey; Bill Masterton

$\mathrm{W}$ ILLIAM "Bill" Masterton is the only man to die of injuries suffered during a National Hockey League (NHL) game. He remains the last fatality in any professional team sport involving a direct ingame injury in North America. Despite playing only 38 career NHL games, he changed hockey, and the way we think about contact sports, forever.

On January 13, 1968, Masterton, playing for the Minnesota North Stars, was checked by Oakland Seals players Ron Harris and Larry Cahan, knocking him to the ice. As was the case with nearly all hockey players at the time, Masterton was not wearing a helmet. He suffered severe head injuries as a direct result of the fall and immediately lost consciousness (Fig. 1). He was taken directly to the hospital, where he died 2 days later at the age of 29 years. ${ }^{1}$ His memory lives on through not only a trophy that bears his name, but also the legacy of bringing head safety to the forefront of a game that was both unready and unwilling to accept change. This paper explores the death of Bill Masterton and the long-lasting effects that it had on head injury and protection in sports.

\section{The Hit}

By all accounts, the check that injured Masterton was not dirty or particularly violent. He appeared to go in and out of consciousness during the fall and thus was unable to protect his head from directly impacting the ice. Teammate Dave Balon was the first to reach Masterton. Balon recalled Masterton looking up at him and muttering, "never again, never again," before losing consciousness for the final time..$^{12}$ Masterton was bleeding from the ears, nose,

ABBREVIATIONS CTE = chronic traumatic encephalopathy; NFL = National Football League; NASCAR = National Association for Stock Car Auto Racing; NHL = National Hockey League.

SUBMITTED February 9, 2015. ACCEPTED February 23, 2016.

INCLUDE WHEN CITING DOI: 10.3171/2016.2.FOCUS1558. 


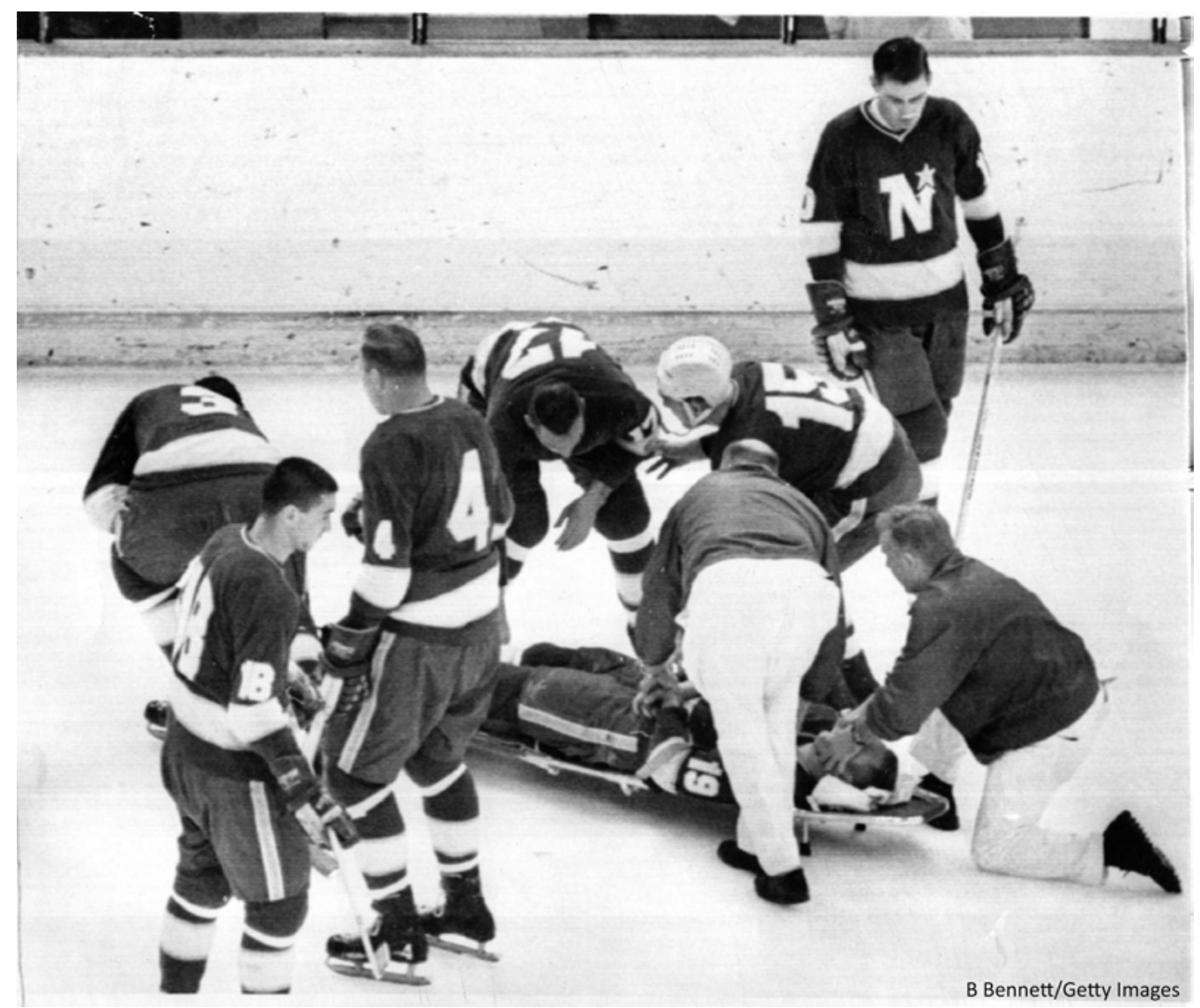

FIG. 1. Bill Masterton, No. 19 of the Minnesota North Stars, lies unconscious from a hit during an NHL game against the Oakland Seals on January 13,1968, at the Met Center in Minneapolis, Minnesota. Trainer Stan Waylett and assistant trainer Al Schuerman (kneeling) help as players Elmer Vasko (No. 4), Dave Balon (No. 17), Andre Boudrias (No. 15), and Ray Cullen (No. 10) look on. Photographer: B Bennett; SPO:98675365, Getty Images Editorial. Reproduced with permission from Getty Images.

and mouth as he was taken off the ice and to the hospital, where he was placed under the care of 2 neurosurgeons and 3 other physicians. His head injury was deemed too severe for surgical intervention, and he died 30 hours after the injury. ${ }^{1}$

Postmortem investigations uncovered evidence that an earlier, untreated head injury was likely partially responsible for Masterton's death. In 2011, University of Toronto neurosurgeon Dr. Charles Tator, who reviewed the case and autopsy, believed that Masterton suffered from second-impact syndrome. He stated, "There is evidence of massive brain swelling ... that is out of proportion to the blow that he got. My interpretation is that the seeds of this catastrophic injury were sown days before." Subsequent interviews revealed that Coach Wren Blair had urged Masterton to get evaluated by team doctors, believing that he had suffered previous concussions. Teammates recall him blacking out on occasion during practices. It was also discovered that Masterton had confided in goalie Cesare Maniago that he had been struggling with migraines believed to be related to a head check during a recent game..$^{23}$ Despite these concerns, Masterton refused to seek medical attention and never missed a practice or a game. Ironically, the perseverance and dedication to hockey, for which Mas- terton is largely remembered, may have ultimately contributed to his death.

\section{Helmets}

In 1968, at the time of Masterton's death, fewer than 20 players in the NHL wore helmets, and most had already suffered a brain injury at some point in their career. ${ }^{12} \mathrm{Hel}-$ met use was seen as weak and against the "warrior code" of hockey. Players claimed they could be cut or traded if they wore helmets. ${ }^{23}$ When Jacques Plante became the first player to routinely wear a goalie mask in 1959, he was heavily criticized. ${ }^{16}$ By that time, however, he had sustained multiple broken noses, a broken jaw, 2 broken cheekbones, and countless stitches to his face.

Masterton's death sparked an immediate debate in the NHL on whether the use of helmets should be compulsory. ${ }^{1}$ Just 4 days after Masterton's death, the NHL Players' Association issued a statement urging the league to adopt mandatory helmet legislation. ${ }^{12}$ At the same time, legislators in New York drafted a similar law. ${ }^{25}$ The National Football League (NFL) had made helmets mandatory in 1943, and Major League Baseball had adopted helmet use as well. All participants in Canadian junior hockey 
leagues wore helmets, and after Masterton's death, all amateur leagues also required helmets. ${ }^{9}$

However, even with the debate ramping up, the NHL remained unconvinced. League president Clarence Campbell downplayed the incident stating, "It was a routine accident that could have happened in any hockey game . . . a normal hazard of the occupation. Helmets are optional now, and we think that is the best method of dealing with it." ${ }^{\prime 2}$ Hockey owners and coaches suggested that an increase in helmet use would create a deep recession in interest in the game and that fans would not be able to recognize the players. Colorado Rockies coach Don Cherry replied, "Next, they'll have everyone in armor. What they've done is taken the identity out of the hockey player."14 Players had excuses as well, citing decreased vision, an increase in heat and discomfort, and the potential for increased dirty play. ${ }^{9}$ Chicago Blackhawks player Doug Wilson mentioned in 1979, “I just don't like helmets. When I had a couple of concussions last year, I had to wear a helmet, but as soon as I could I quit, I think I play better without it." ${ }^{14}$ However, other reports claimed that players actually wanted helmets, but that their coaches would think of them as cowardly. ${ }^{24}$ Chicago's Stan Mikita, the NHL's reigning most valuable player at the time, immediately began wearing a helmet after the Masterton tragedy. Other players followed. ${ }^{16}$

Adopting helmet use in the NHL was slow. By 1971, the league had 3 times voted and rejected a rule requiring players to wear helmets. ${ }^{24}$ Even in Minnesota, only 6 players wore helmets, the most by any team in the league. ${ }^{2}$ Eventually, 11 years after Masterton's death, the NHL finally mandated the use of helmets by all players entering the league beginning in the 1979-1980 season. ${ }^{3}$ By that time, over $70 \%$ of the league's players were wearing helmets. ${ }^{12}$ Players who had signed a professional contract before June 1 of that year still had the option of refusing to wear one. In 1997, Craig MacTavish retired from hockey as the last player not to wear a helmet. As Masterton's Minnesota teammate Ray Cullen stated in 2008, "It's ridiculous that we thought that way back then, but we did. It took Bill dying for all of us to start thinking, 'What are we doing?"'16 In today's NHL, it is unthinkable that any player would step on the ice without wearing a helmet.

\section{Legacy}

Several awards have been created in memory of Bill Masterton. In 1968, the Professional Hockey Writers Association created the Bill Masterton Memorial Trophy. It has been given annually since then to the "National Hockey League player who best exemplifies the qualities of perseverance, sportsmanship, and dedication to hockey." The first winner of the trophy was Claude Provost following the 1967-1968 season. Other famous winners include Bobby Clarke, Steve Yzerman, Cam Neely, and Mario Lemieux (http://www.hhof.com/htmlSilverware/ silver_splashbillmasterton.shtml). The University of Denver's most valuable player award is named after Masterton. ${ }^{11}$ Furthermore, the Minnesota North Stars immediately pulled Masterton's number 19 out of circulation after his death and formally retired it in 1987. The number now remains retired in Dallas, where the franchise relocated in 1993 (http://stars.nhl.com/club/page.htm?id=39194).

Masterton's legacy extends much beyond the awards that bear his name. An increase in mainstream media attention in recent years has led to an extraordinary public awareness of brain injury and concussion in hockey and other sports..$^{13}$ National Hockey League stars like Sidney Crosby have been sidelined for extended periods of time. Many careers, including those of Chris Pronger, Pat LaFontaine, Eric Lindros, Scott Stevens, and Marc Savard, were prematurely ended in part due to multiple concussions..$^{5}$ Investigations on the long-lasting effects of repeated trauma to the head are in the spotlight after the apparent suicides of 3 NHL "enforcers" (Derek Boogaard, Rick Rypien, and Wade Belak) raised new questions in $2011 .^{6}$ The NHL was the first professional league to initiate protocols to better prevent, recognize, and treat concussions. The NHL Protocol for Concussion Evaluation and Management was created in 1997, and a revised program was implemented in $2011 .{ }^{20}$ Other preventative measures instituted by the NHL include the removal of seamless glass surrounding NHL rinks, additional assessment of ways to modify player equipment to make it safer, and rule changes that levy penalties, fines, and suspensions to players for illegal and dangerous hits.

This increased awareness of traumatic brain injury has reached virtually all forms of sport. The NFL is affected by concussions, which in 2014 resulted in a $\$ 765$ million group settlement with over 4500 former players alleging that the league has been denying a link between playing football and traumatic brain injuries. ${ }^{4}$ Evidence of chronic traumatic encephalopathy (CTE) was discovered in 76 of 79 brains of deceased former professional football players, including legends Mike Webster and Junior Seau (who died of suicide in 2012). ${ }^{7}$ In addition to paying the settlement, the NFL continues to update its return-to-play concussion protocol and charge increased penalties and fines to players for hits to the head. ${ }^{8}$ As a result of this increased awareness, modern testing techniques continue to be used by manufacturers to evaluate and create more effective helmets. ${ }^{22,26}$ Recently, the Summation of Tests for the Analysis of Risk (STAR) equation has been developed, which assesses data from drop tests to predict the injury risk from 1000 exposures for a football player wearing a helmet during one season. ${ }^{21}$

In the area of snow sports, the high-profile deaths of Michael Kennedy, Sonny Bono, and Natasha Richardson due to severe head trauma brought the issue of helmet use among casual skiers to the media forefront. ${ }^{19}$ Recent data from the United States has shown that helmet use has increased significantly from $25 \%$ of skiers and snowboarders in 2003 to $57 \%$ in $2010 .{ }^{15}$ Formal policies and interventions to increase helmet use continue to be promoted to reduce mortality and head injury among skiers and snowboarders worldwide. ${ }^{10,15}$

Similarly, the National Association for Stock Car Auto Racing (NASCAR) saw 4 racers die of basilar skull fractures in 2000-2001 in on-track accidents. ${ }^{18}$ The last of that group was superstar Dale Earnhardt, whose death at the Daytona 500 fueled immediate and continued changes in NASCAR's approach to safety, including 1) mandatory 
wearing of the Head and Neck Support (HANS) device or similar head and neck restraints, 2) opening the NASCAR Research and Development Center in 2002, 3) installing Steel and Foam Energy Reduction (SAFER) barriers at tracks, and 4) introducing in 2007 the Car of Tomorrow (CoT) with improved safety features for races. ${ }^{17}$ Dale Earnhardt remains the last driver to be killed during a vehicle accident in any NASCAR event.

It is through these unfortunate events that the public eye has been opened to the dangers of head injuries in a multitude of professional sports and even nonprofessional sports activity. This increase in public concern has forced the professional sports world to focus additional research on head protection, postconcussive syndrome, secondimpact syndrome, and CTE, and it continues to force policy change regarding the safety of players. The injury that sparked the years of debate surrounding head injury in sports and the later actions that helped to remedy the inherent risks of these sports can be found on January 15, 1968, when Bill Masterton died.

\section{References}

1. Associated Press: Brain injuries takes life of Stars' Bill Masterton. Saskatoon Star-Phoenix. January 16, 1968. (http://news.google.com/newspapers?id=ci5gAAAAIBAJ\&s jid $=028$ NAAAAIBAJ \&pg $=6818,1818123$ ) [Accessed March 11, 2016]

2. Associated Press: Goldsworthy enjoys streak. Calgary Herald. February 16, 1971. (http://news.google.com/new spapers?id=W2tkAAAAIBAJ\&sjid=_3wNAAAAIBAJ\& $\mathrm{pg}=3218,120919)$ [Accessed March 11, 2016]

3. Associated Press: N.H.L. rules new players now must wear helmets. New York Times. August 6, 1979. (http://query. nytimes.com $/ \mathrm{mem} /$ archive-free/pdf?res=980DE3D91239E 432A25754C0A96E9C946890D6CF) [Accessed March 11, 2016]

4. Blair J: In the wake of NFL concussions settlement, will NHL follow suit? Globe and Mail. August 29, 2013. (http://www.theglobeandmail.com/sports/football/in-thewake-of-nfl-concussions-settlement-will-nhl-follow-suit/ article14033493) [Accessed March 11, 2016]

5. Blennerhassett P: The concussion conundrum. Winnipeg Free Press. July 5, 2014. (http://www.winnipegfreepress. com/arts-and-life/life/health/the-concussionconundrum-265876911.html) [Accessed March 11, 2016]

6. Branch J: Hockey players' deaths pose a tragic riddle. New York Times. September 1, 2011. (http://www.nytimes. com/2011/09/02/sports/hockey/deaths-of-three-nhl-playersraises-a-deadly-riddle.html?pagewanted=all) [Accessed March 11, 2016]

7. Breslow JM: 76 of 79 deceased NFL players found to have brain disease. PBS Frontline. September 30, 2014. (http:// www.pbs.org/wgbh/pages/frontline/sports/concussionwatch/76-of-79-deceased-nfl-players-found-to-have-braindisease) [Accessed March 11, 2016]

8. Breslow JM: With eye on concussions, NFL adopts new rule on helmet hits. PBS Frontline. March 22, 2013. (http://www. pbs.org/wgbh/pages/frontline/sports/concussion-watch/witheye-on-concussions-nfl-adopts-new-rule-on-helmet-hits) [Accessed March 11, 2016]

9. Canadian Press: Swing to helmets considered unlikely. Saskatoon Star-Phoenix. January 16, 1968. (http://news. google.com/newspapers?id=ci5gAAAAIBAJ\&sjid=028NAA AAIBAJ\&pg=6818,1818123) [Accessed March 11, 2016]
10. Cusimano MD, Kwok J: The effectiveness of helmet wear in skiers and snowboarders: a systematic review. Br J Sports Med 44:781-786, 2010

11. DenverPioneers.com: Denver hockey holds annual awards banquet at cable center. (http://www.denverpioneers.com/ sports/m-hockey/spec-rel/042014aaa.html) [Accessed March 11, 2016]

12. Fitzpatrick F: Giving 'em Fitz: Masterton's death a haunting memory. Philly.com. January 12, 2015. (http://articles.philly. com/2015-01-12/sports/57946072_1_hockey-bill-mastertonfirst-nhl-game) [Accessed March 11, 2016]

13. Garofalo P: For NHL players, concussions last a lifetime. U.S. News \& World Report. April 22, 2013. (http://www. usnews.com/opinion/blogs/pat-garofalo/2013/04/22/studyshows-nhl-concussions-last-a-lifetime) [Accessed March 11, 2016]

14. Gray D: NHLers oppose mandatory helmet rule. TheLeafsNation.com. March 11, 2011. (http://theleafsnation. com/2011/9/14/a-brief-history-of-the-nhls-resistance-tochange) [Accessed March 11, 2016]

15. Haider AH, Saleem T, Bilaniuk JW, Barraco RD: An evidence-based review: efficacy of safety helmets in the reduction of head injuries in recreational skiers and snowboarders. J Trauma Acute Care Surg 73:1340-1347, 2012

16. Heika M: North Star player's death 40 years ago changed the game of hockey forever. Minneapolis-St. Paul Star Tribune. January 15, 2008. (http://www.startribune.com/ templates/Print_This_Story?sid=13797041) [Accessed March 11, 2016]

17. Hinton E: Earnhardt's death a watershed moment. ESPN. com. February 14, 2011. (http://sports.espn.go.com/rpm/ nascar/cup/columns/story?id=6116145) [Accessed March 11, 2016]

18. Libaw O, Dubrow E, Maier D: NASCAR star Dale Earnhardt dies in race. ABCNews.com. February 18, 2001. (http:// abcnews.go.com/Sports/story?id=99829) [Accessed March 11, 2016]

19. Robbins L: Richardson's accident reignites ski helmet debate. New York Times. March 18, 2009. (http://thelede.blogs. nytimes.com/2009/03/18/richardsons-accident-reignites-skihelmet-debate) [Accessed March 11, 2016]

20. Rosen D: New concussion protocol goes into effect tonight. NHL.com. March 16, 2011. (http://www.nhl.com/ice/news. htm?id=556289) [Accessed March 11, 2016]

21. Rowson S, Duma SM: Development of the STAR evaluation system for football helmets: integrating player head impact exposure and risk of concussion. Ann Biomed Eng 39:2130 2140,2011

22. Rowson S, Duma SM, Greenwald RM, Beckwith JG, Chu JJ, Guskiewicz KM, et al: Can helmet design reduce the risk of concussion in football? J Neurosurg 120:919-922, 2014

23. Starkman R: What really killed NHL's Bill Masterton. Toronto Star. May 28, 2011. (http://www.thestar.com/sports/ hockey/2011/05/28/star_investigation_what_really_killed_ nhls_bill_masterton.html) [Accessed March 11, 2016]

24. United Press International: Helmet-maker uses space material. Montreal Gazette. November 2, 1971. (http://news. google.com/newspapers?nid=1946\&dat=19711102\&id=EEE jAAAAIBAJ\&sjid=36EFAAAAIBAJ \&pg=5024,8006343) [Accessed March 11, 2016]

25. Vancouver Sun: Injury shelves 'Shoe.' January 24, 1968. (http://news.google.com/newspapers?id=q5Z1AAAAIBAJ\& sjid=vooNAAAAIBAJ\&pg=764,2634193] [Accessed March 11, 2016]

26. Viano DC, Withnall C, Halstead D: Impact performance of modern football helmets. Ann Biomed Eng 40:160-174, 2012 


\section{Disclosures}

The authors report no conflict of interest concerning the materials or methods used in this study or the findings specified in this paper.

\section{Author Contributions}

Conception and design: both authors. Acquisition of data: Bonfield. Analysis and interpretation of data: Bonfield. Draft- ing the article: both authors. Critically revising the article: both authors. Reviewed submitted version of manuscript: both authors. Approved the final version of the manuscript on behalf of both authors: Bonfield. Administrative/technical/material support: Kondziolka. Study supervision: Kondziolka.

\section{Correspondence}

Christopher M. Bonfield, Department of Neurological Surgery, Vanderbilt University Medical Center, 2220 Children's Way, 9226 Doctors' Office Tower, Nashville, TN 37232. email: chris. bonfield@vanderbilt.edu. 